Relations industrielles

Industrial Relations

\title{
"Les hôpitaux dans la Province de Québec ", Département d'Action Sociale, Conférence Catholique Canadienne, Ottawa 1961, 103 pp.
}

\section{Claude Morin}

Volume 17, numéro 1, janvier 1962

URI : https://id.erudit.org/iderudit/1021665ar

DOI : https://doi.org/10.7202/1021665ar

Aller au sommaire du numéro

Éditeur(s)

Département des relations industrielles de l’Université Laval

ISSN

0034-379X (imprimé)

1703-8138 (numérique)

Découvrir la revue

Citer ce compte rendu

Morin, C. (1962). Compte rendu de ["Les hôpitaux dans la Province de Québec ", Département d'Action Sociale, Conférence Catholique Canadienne, Ottawa 1961, 103 pp.] Relations industrielles / Industrial Relations, 17(1), 93-93. https://doi.org/10.7202/1021665ar

Tous droits réservés (C Département des relations industrielles de l’Université Laval, 1962
Ce document est protégé par la loi sur le droit d'auteur. L'utilisation des services d'Érudit (y compris la reproduction) est assujettie à sa politique d'utilisation que vous pouvez consulter en ligne.

https://apropos.erudit.org/fr/usagers/politique-dutilisation/ 
- Les hôpitaux dans la Province de Québec \$, Département d'Action Sociale, Conférence Catholique Canadienne, Ottawa 1961, 103 pp.

Les problèmes relatifs à la protection de la santé constituent une des préoccupations actuelles les plus profondes aussi bien des gouvernants, que des mouvements ouvriers et des citoyens en général. L'assurance-santé donne un excellent exemple de cet état d'esprit: alors qu'il n'en était que vaguement question il a quelques années, elle fournit maintenant une source abondante de publicité électorale aux principaux partis politiques canadiens.

Or, dans ce vaste domaine, une mesure de sécurité sociale bien connue est déjà à l'épreuve dans toutes les provinces du pays: l'assurance-hospitalisation. Il est maintenant possible de se rendre compte de ses avantages, de ses inconvénients et de ses limitations. Elle suscite maintes discussions, surtout dans le Québec où elle n'a qu'un peu plus d'un an d'existence. On peut donc dire que la brochure cLes hôpitaux dans la Province de Québec s vient à point. Comme son nom lindique, elle touche les hôpitaux du Québec et renferme une impressionnante documentation sur les institutions hospitalières de la Province: confessionalité, année d'incorporation, genre, situation géographique, capacité, nom des directeurs, etc. C'est ainsi que le lecteur apprendra que, contrairement à la croyance populaire, la majorité des hôpitaux québecois $(64.5 \%)$ appartiennent à des laīcs; ceux-ci ne représentent toutefois que $\mathbf{4 1 . 5 \%}$ de la capacité totale en lits.

Cependant l'intérêt de cette brochure nous apparait résider moins dans son aspect statistique, bien que celui-ci soit très utile, que dans la collection de documents qu'elle présente sur le programme d'assurance-hospitalisation lui-même et sur certains événements historiques.

On ne peut en effet trouver à aucun autre endroit, colligés dans une même brochure, des textes comme ceux de la loi fédérale d'assurance-hospitalisation, des amendements à cette loi, de la loi provinciale de 1960 et de ses règlements. On peut aussi y consulter une copie du contrat hôpital-gouvernement, ainsi que deux mémoires soumis par des associations d'hôpitaux québecois à la Commis- sion Royale d'enquête sur l'assurancehospitalisation.

Dans la catégorie des documents historiques, on trouvera plusieurs déclarations officielles de l'épiscopat sur les problèmes hospitaliers et certains communiqués qui démontrent le souci longtemps manifesté par l'autorité religieuse de coordonner et d'unifier l'action des quatre grandes associations hospitalières confessionnelles du Québec. D'ailleurs une des sections de la brochure contient justement une précieuse documentation sur ces diverses associations.

La brochure \& Les hôpitaux dans la Province de Québec » s'avèrera certainement d'une grande utilité pour ceux qu'intéressent le problème hospitalier dans toutes ses dimensions: législation, unification des efforts, conformité par rapport aux besoins, etc. Cet ouvrage étant le premier de la série dite $<$ Hôpitaux $\gg$, il était logique qu'il contienne tous ces renseignements fondamentaux. Il serait à souhaiter que les autres qui lui succéderont s'attachent à des études de situations concrètes, à des analyacs de tendances et même à des exposés sur les problèmes financiers des institutions hospitalières. Si elle avait pu poursuivre son travail, la Commission Royale d'enquête sur l'assurance-hospitalisation aurait certainement livré au public québecois une intéressante documentation sur ces sujets; si on en juge par sa première publication sur les hôpitaux, le Département d'Action Sociale de la Conférence Catholique Canadienne semble devoir combler cette lacune.

Claude Morun

The Catholic Movement of Employers and Managers. By Joseph B. Gremillon. Gregorian University Press, 4 Piazza della Pilotta, Rome, 1961, 217 pages.

Ce volume est la publication d'une thèse préparée par l'auteur à l'Université Grégorienne de Rome sur l'Union internationale des associations patronales catholiques. (UNIAPAC)

Dans un court chapitre, l'auteur, qui est prêtre américain, présente ce groupement fondé officiellement en 1949, mais qui est la continuation d'une autre organisation mise sur pied en 1931. Il prend la peine de noter que le sujet de 